\title{
DORMÊNCIA E ARMAZENABILIDADE DE SEMENTES DE CAPIM-GORDURA ${ }^{1}$
}

\author{
RICARDO CARMONA², CARLOS ROMERO MARTINS ${ }^{3}$
}

\begin{abstract}
RESUMO - A gramínea africana Melinis minutiflora (capim-gordura), que foi a base da pecuária no Centro-Oeste brasileiro durante aproximadamente dois séculos, é atualmente considerada uma importante planta invasora nessa região. $\mathrm{O}$ trabalho foi realizado com o objetivo de avaliar dois aspectos relacionados às sementes que podem influenciar o potencial disseminador dessa espécie - a dormência e a armazenabilidade. As sementes das cultivares Roxo e Cabelo-de-Negro foram armazenadas em ambiente de laboratório em Brasília-DF, sendo sua germinação testada periodicamente tanto nas temperaturas alternadas de $20-30{ }^{\circ} \mathrm{C}$ (16/8 horas), com luz fluorescente branca durante a temperatura mais elevada, empapel filtro umedecido com nitrato de potássio a $0,5 \%$, como na temperatura de $25^{\circ} \mathrm{C}$ no escuro e em água. As sementes recém-colhidas de ambas cultivares apresentaram viabilidade de aproximadamente $100 \%$ e alta dormência primária. A viabilidade das sementes armazenadas em laboratório manteve-se elevada (igual ou superior a 90\%) pelo período de três anos, sendo que mesmo após oito anos de armazenamento nessas condições algumas sementes ainda preservaram a capacidade germinativa. Nas condições de temperaturas alternadas, o tempo médio de germinação das sementes é de 4,3 e de 4,4 dias para as cultivares Roxo e Cabelo-de-Negro. Foi necessário o período de 3,8 anos para a superação completa da dormência das sementes em armazenamento. A elevada viabilidade associada à dormência, longevidade e rápida germinação observadas no presente trabalho ajudam a explicar o sucesso dessa espécie em colonizar novas áreas.
\end{abstract}

Termos para indexação: biologia, ecologia, colonização, viabilidade de sementes.

\section{DORMANCY AND STORAGE POTENTIAL OF MELINIS MINUTIFLORA SEEDS}

\begin{abstract}
The African grass species, Melinis minutiflora, which was an important forage species in the Brazilian Cerrado region for around two centuries, is nowadays considered an important weed in this region. The present study aimed to evaluate seed dormancy and viability during storage, aspects that could affect species dissemination. Seeds of the cultivars Roxo and Cabelo-de-Negro stored under laboratory conditions in Brasília-DF, Brazil, were tested periodically, both at alternating temperatures of $20-30{ }^{\circ} \mathrm{C}(16 / 8$ hours), with white fluorescent light during the highest temperature, plus potassium nitrate at $0.5 \%$, and at $25{ }^{\circ} \mathrm{C}$ in darkness and in water. Recently-harvested seeds of both cultivars showed approximately $100 \%$ viability and a high primary dormancy level. Seed viability remained high for around three years (at least $90 \%$ ), and even after eight years of storage under these conditions some seeds remained viable.
\end{abstract}

${ }^{1}$ Submetido em 24/04/2009. Aceito para publicação em 06/08/2010.

${ }^{2}$ Eng. Agrônomo, PhD, Universidade de Brasília, Faculdade de Agronomia e Medicina Veterinária, Caixa Postal 04508, Cep: 70910-970, BrasíliaDF, e-mail: rcarmona@unb.br.
${ }^{3}$ Eng. Florestal, Doutor, Ibama/DILIC/CGTMO/COMOC, SCEN Trecho 2 - Ed. Sede - Bloco "C" $1^{\circ}$ Andar, Caixa Postal 09870, CEP 70.818-900 Brasília, DF. E-mail: carlos.martins@ibama.gov.br. 


\begin{abstract}
At alternating temperatures, the average germination period is 4.3 days for the Roxo cultivar and 4.4 days for Cabelo-de-Negro. Seed dormancy was completely overcome after 3.8 years of storage. The high seed viability, dormancy and germination speed observed in this study help to explain the success of this species in colonizing new areas.
\end{abstract}

Index terms: biology, ecology, colonization, seed viability.

\section{INTRODUÇÃO}

O gênero Melinis (capim-gordura) contém de 20 a 25 espécies, sendo que apenas Melinis minutiflora e $M$. repens ocorrem no território brasileiro. O capim-gordura é uma planta perene, herbácea, de metabolismo $\mathrm{C}_{4}$, que apresenta altura média entre 0,40 e $0,60 \mathrm{~m}$, podendo chegar até a $1 \mathrm{~m}$ ou mais. Apresenta ampla distribuição geográfica, podendo ser encontrado em regiões tropicais e subtropicais, entre $30^{\circ}$ de latitude norte e sul do equador. Encontra-se amplamente distribuído em vários países da África, das Américas, da Ásia e da Oceania. Desenvolve-se melhor em altitudes entre 200 e $2.300 \mathrm{~m}$, com temperaturas entre $18^{\circ}$ e $27^{\circ} \mathrm{C}$, e a sua ocorrência está mais limitada pelas baixas temperaturas do que pela qualidade do solo. É pouco exigente em fertilidade, vegetando bem em solos ácidos, mas não tolera solos pesados e muitos argilosos (Martins et al., 2009).

A espécie Melinis minutiflora P. Beauv. (capimgordura), de origem africana, foi introduzida no Brasil no século XIX, de forma acidental, por ocasião do tráfico intenso de escravos que ocorreu no período colonial (Filgueiras, 1990). Na década de 1960, existia no território brasileiro uma área de aproximadamente 123 milhões de hectares cobertos com pastagens. Desse total, cerca de 30 milhões de hectares eram utilizados para gado leiteiro, que tinha como principal gramínea forrageira a espécie Melinis minutiflora (Teixeira, 1984).

Em decorrência de essa espécie apresentar baixa produtividade, baixa capacidade de lotação (Carvalho et al. 1988), não suportar pastoreio intensivo e praguejar com relativa facilidade, nas últimas três décadas essa gramínea tem tido alvo de um programa de substituição principalmente por espécies dos gêneros Brachiaria (=Urochloa), Andropogon e Panicum (=Urochloa), trazidas do continente africano (Macedo, 2000). Estimase que no Centro-Oeste brasileiro existem cerca de 60 milhões de ha de pastagens cultivadas, sendo que deste total apenas 1,8 milhões de ha são ocupados pelos gêneros Andropogon, Cynodon e Melinis (Macedo, 2005). Os principais remanescentes de pastagens cultivadas de capim-gordura no Brasil ocorrem na região Sudeste. A maioria das áreas ocupadas por essa gramínea apresenta relevo acidentado, com solos ácidos e de baixa fertilidade natural.

O capim-gordura foi considerado uma das principais invasoras no Centro-Oeste brasileiro (Filgueiras, 2005), especialmente em unidades de conservação como: Parque Nacional de Brasília - DF, Reserva Biológica de Águas Emendadas - DF, Parque Nacional das Emas GO, Parque Nacional Serra da Canastra - MG, Floresta Nacional de Ipanema - SP, entre outras (Carmona e Martins, 2009).

Produz grande quantidade de sementes $(200-280 \mathrm{~kg} /$ ha), com alto poder germinativo, e reprodução vegetativa por meio de estolões (Skerman e Rivers, 1992). Outros fatores como viabilidade e dormência de sementes recém-colhidas, caso fossem pronunciados, poderiam ainda afetar o potencial disseminador dessa espécie (Carmona e Murdoch, 1995).

O objetivo do presente trabalho foi de avaliar a redução da dormência e da viabilidade de sementes durante o armazenamento de duas variedades cultivadas de Melinis minutiflora que atualmente colonizam espontaneamente áreas de vegetação nativa no CentroOeste brasileiro.

\section{MATERIAL E MÉTODOS}

\section{Coletas de sementes}

Unidades de dispersão de capim-gordura (espiguetas cheias e vazias) das cultivares Roxo e Cabelo-de-Negro, doravante referidas como sementes, foram coletadas no Parque Nacional de Brasília (coordenadas $15^{\circ} 44^{\prime}$ S e 47 ${ }^{\circ} 57^{\prime} \mathrm{W}$ ). Para fins de coleta, foram cortadas manualmente e aleatoriamente cerca de $3 \mathrm{~kg}$ de inflorescências de cada cultivar, no mês de junho de 1999, mediante o método de caminhamento através de transectos imaginários. O material cortado foi seco a sombra, pelo período de dois meses, no Laboratório de sementes da Faculdade de 
Agronomia e Medicina Veterinária da Universidade de Brasília. O material foi trilhado e limpo manualmente e as sementes acondicionadas em sacos de papel permeável e armazenadas em laboratório sob condições ambientais em Brasília-DF, por um período de 8 anos.

Condições climáticas do local de armazenamento

O clima em Brasília é tropical de altitude, com verão úmido e chuvoso e inverno seco e relativamente frio. A umidade relativa média do ar varia de $50 \%$ a $70 \%$ durante os meses mais chuvosos (outubro a março), e de $20 \%$ a $40 \%$ nos meses mais secos (abril a setembro) (INMET, 2010). Durante o experimento (1999 a 2007), as temperaturas máxima média, média e mínima média foram, respectivamente, de $25,4{ }^{\circ} \mathrm{C}, 22,0{ }^{\circ} \mathrm{C}$ e $18,5{ }^{\circ} \mathrm{C}$ (Tabela 1).

TABELA 1. Temperaturas máxima média, média e mínima média mensais $\left({ }^{\circ} \mathrm{C}\right)$ em Brasília, DF no período do experimento (1999 a 2007).

\begin{tabular}{lrrrrrrrrrrrrr}
\hline \multicolumn{1}{c}{ Mês } & Jan & Fev & Mar & Abr & Mai & Jun & Jul & Ago & Set & Out & Nov & Dez & Ano \\
\hline Temperatura máxima média & 25,4 & 25,5 & 27,6 & 26,5 & 26,0 & 22,0 & 23,3 & 26,3 & 28,3 & 26,3 & 23,6 & 24,3 & 25,4 \\
Temperatura média & 22,9 & 23,0 & 23,0 & 22,6 & 21,2 & 20,2 & 20,0 & 21,1 & 22,6 & 23,0 & 21,7 & 22,6 & 22,0 \\
Temperatura mínima média & 19,2 & 20,9 & 20,0 & 18,3 & 18,3 & 18,4 & 16,0 & 16,8 & 18,4 & 19,0 & 18,9 & 18,4 & 18,5 \\
\hline
\end{tabular}

Fonte:<http://www.ciiagro.sp.gov.br/ciiagroonline/Quadros/QTmedPeriodo.asp>. Acesso em: 29 Julho 2010.

\section{Parâmetros avaliados}

Os testes de germinação foram conduzidos apenas com sementes cheias. As espiguetas cheias foram separadas das vazias mediante uso de assoprador (marca General Seed Blower) por três minutos, previamente regulado na abertura 8. Devido à ocorrência de aristas nas sementes da cv. Roxo, em cada operação no assoprador o peso máximo da porção de sementes não excedeu a 0,10 g para evitar o entrelaçamento entre as sementes.

Os ensaios de germinação iniciaram no mês de agosto de 1999 e se estenderam até outubro de 2007, sendo as sementes testadas em agosto/99, setembro/99, outubro/99, novembro/99, dezembro/99, janeiro/00, fevereiro/00, março/00, abril/00, junho/00, agosto/00, outubro/00, dezembro/00, fevereiro/01, abril/01, maio/01, junho/01, julho/01, outubro/01, março/02, maio/02, outubro/02, março/03, maio/03, outubro/03, maio/04, outubro/04, maio/05, outubro/05, outubro/06 e outubro/07. Os testes de germinação foram conduzidos em câmaras de germinação nas temperaturas alternadas de $20^{\circ}-30{ }^{\circ} \mathrm{C}$ (16/8horas) com luz fluorescente branca durante a temperatura mais elevada e nitrato de potássio a $0,5 \%$, e na temperatura de $25^{\circ} \mathrm{C}$ no escuro e em água.

As condições descritas para o teste em temperaturas alternadas, por serem altamente estimulantes de germinação para várias espécies de gramíneas (Carmona et al., 1998), foram testadas para estimar a viabilidade das sementes. Já as condições de temperatura constante foram usadas para estimar a dormência das sementes (Carmona et al., 1998). Os testes de germinação foram realizados sobre papel, em placas de petri de poliestireno transparente forradas com duas folhas de papel filtro umedecidas com nitrato de potássio ou água, conforme o teste.

As avaliações de germinação foram realizadas diariamente nos testes em presença de luz, a fim de monitorar-se a evolução do processo germinativo, reumedecendo-se o substrato com água destilada sempre que necessário. Os testes na ausência de luz foram conduzidos envolvendo-se cada placa de petri com duas folhas de papel alumínio. Nesse caso, as placas foram seladas com fita adesiva para evitar o ressecamento do substrato.

Todos os tratamentos constaram de quatro repetições de 100 sementes cheias (Brasil, 2009) em delineamento inteiramente casualizado. Os testes no escuro foram avaliados uma única vez, ao final das avaliações em presença de luz. Considerou-se germinada a semente que emitiu pelo menos $2 \mathrm{~mm}$ de radícula e/ou coleóptilo.

Calculou-se o tempo médio de germinação (TMG), expresso em dias, por meio da seguinte fórmula: $\mathrm{TMG}=\frac{\sum(T . N)}{\sum N}$, em que $\mathrm{N}$ é o número de sementes que germinaram e $\mathrm{T}$ é o número de dias.

Os dados de germinação ao longo do tempo, para ambas cultivares, foram submetidos a análise de regressão, mediante o programa estatístico SAS. 


\section{RESULTADOS E DISCUSSÃO}

As sementes recém-colhidas das cultivares Cabelode-Negro e Roxo e Cabelo-de-Negro de M. minutiflora apresentaram germinação próxima a $100 \%$ quando expostas a luz, nitrato de potássio e temperaturas alternadas $\left(20-30{ }^{\circ} \mathrm{C}\right)$, mantendo-se acima de $90 \%$ por um período de cerca de três anos (Figuras 1 e 2). O comportamento germinativo das sementes das duas cultivares foi semelhante nessas condições. O potencial de armazenamento das sementes de capim-gordura observado no presente trabalho é superior ao observado por Andrade (1983), em que o início do decréscimo de viabilidade ocorreu aos nove meses após a colheita, sendo as sementes testadas sob temperaturas alternadas de 20$30{ }^{\circ} \mathrm{C}(8 / 16 \mathrm{~h})$, com luz. Pelo menos dois aspectos podem explicar essa diferença - as condições ambientais durante o armazenamento e a qualidade fisiológica das sementes ao início do armazenamento.

Comparando os resultados encontrados neste estudo com os dados apresentados por Carmona et al. (1999), é possível observar que a germinação de sementes recémcolhidas do capim-gordura sob temperaturas alternadas supera a germinação de muitas gramíneas nativas da região do Cerrado, que apresentaram uma variação na percentagem de germinação entre $2 \%$ e $97 \%$. Segundo esses autores, a grande variabilidade encontrada pode ser explicada principalmente pela diferença de dormência entre as sementes das espécies estudadas.

Avaliações conduzidas com gramíneas africanas cultivadas no Brasil revelam que a porcentagem de germinação das espécies Andropogon gayanus e Brachiaria decumbens (Urochloa decumbens) é normalmente inferior à do capim-gordura. A espécie Andropogon gayanus apresenta uma variação na germinação de $57 \%$ a $70 \%$. Por sua vez, a porcentagem de sementes germinadas na espécie Brachiaria decumbens varia de $29 \%$ a $85 \%$ (Condé e Garcia, 1985; Eira, 1983; Klink, 1996; Sader et al., 1991).

Os resultados confirmam que as sementes de capimgordura podem ser classificadas como de vida longa (Figuras 1 a 4). Mesmo após 8 anos de armazenamento em condições ambientais predominantes em BrasíliaDF, cerca de $40 \%$ das sementes de capim-gordura ainda mantinham capacidade de germinação no presente trabalho (Figuras 1 a 4). Rocha et al. (1996) observaram um pequeno potencial germinativo nas sementes dessa espécie após cinco anos de armazenamento em temperatura ambiente.

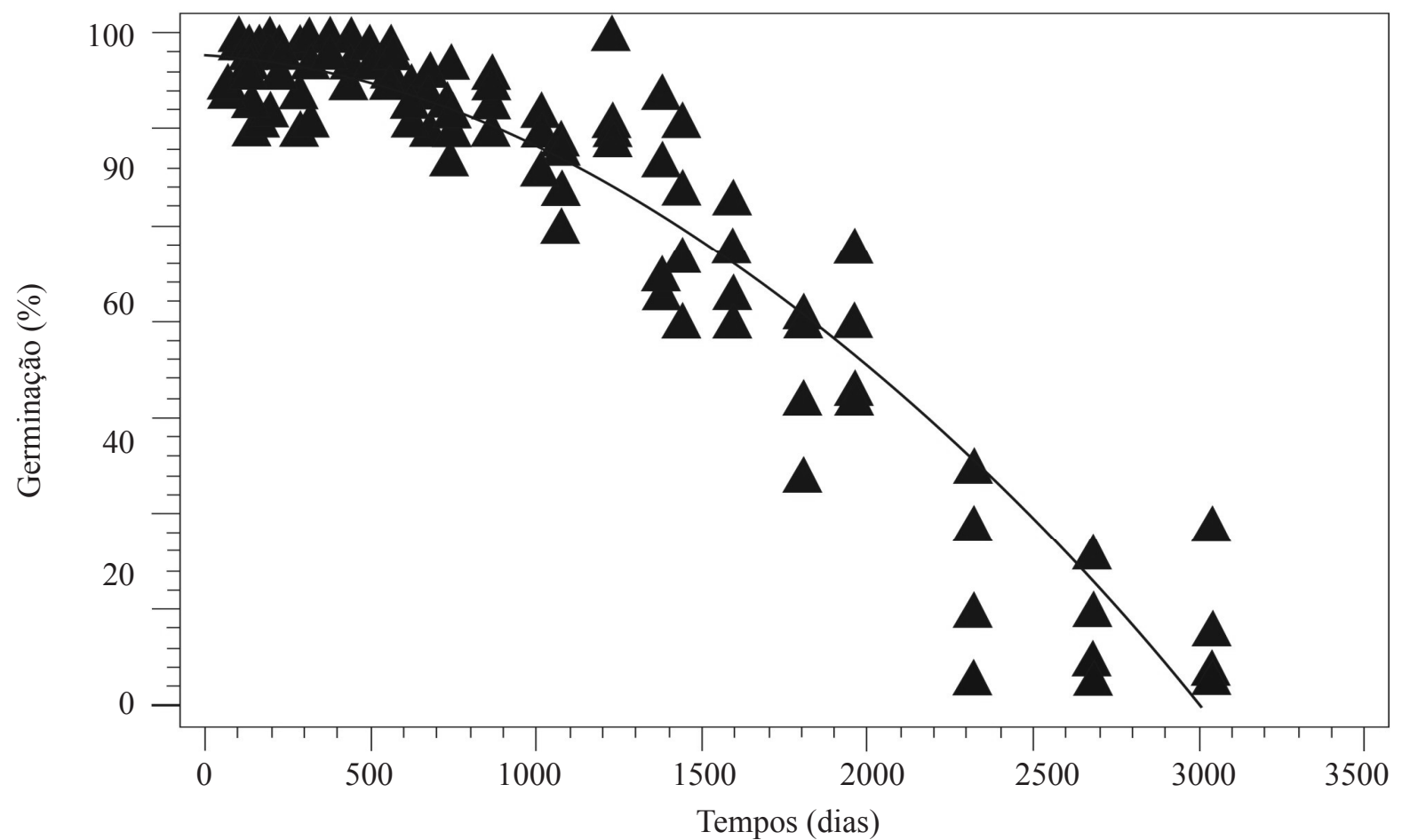

FIGURA 1. Germinação de sementes (\%) de $M$. minutiflora variedade Cabelo-de-Negro a 20/30 ${ }^{\circ} \mathrm{C}$, em presença de luz e nitrato de potássio ao longo do tempo de armazenamento em condições ambientais, em BrasíliaDF. $\left(\right.$ germinação $=97.9877-0.003401 *$ Dias $\left.-6.394 E-6 * \operatorname{Dias}^{2}, r^{2}=0,90\right)$. 


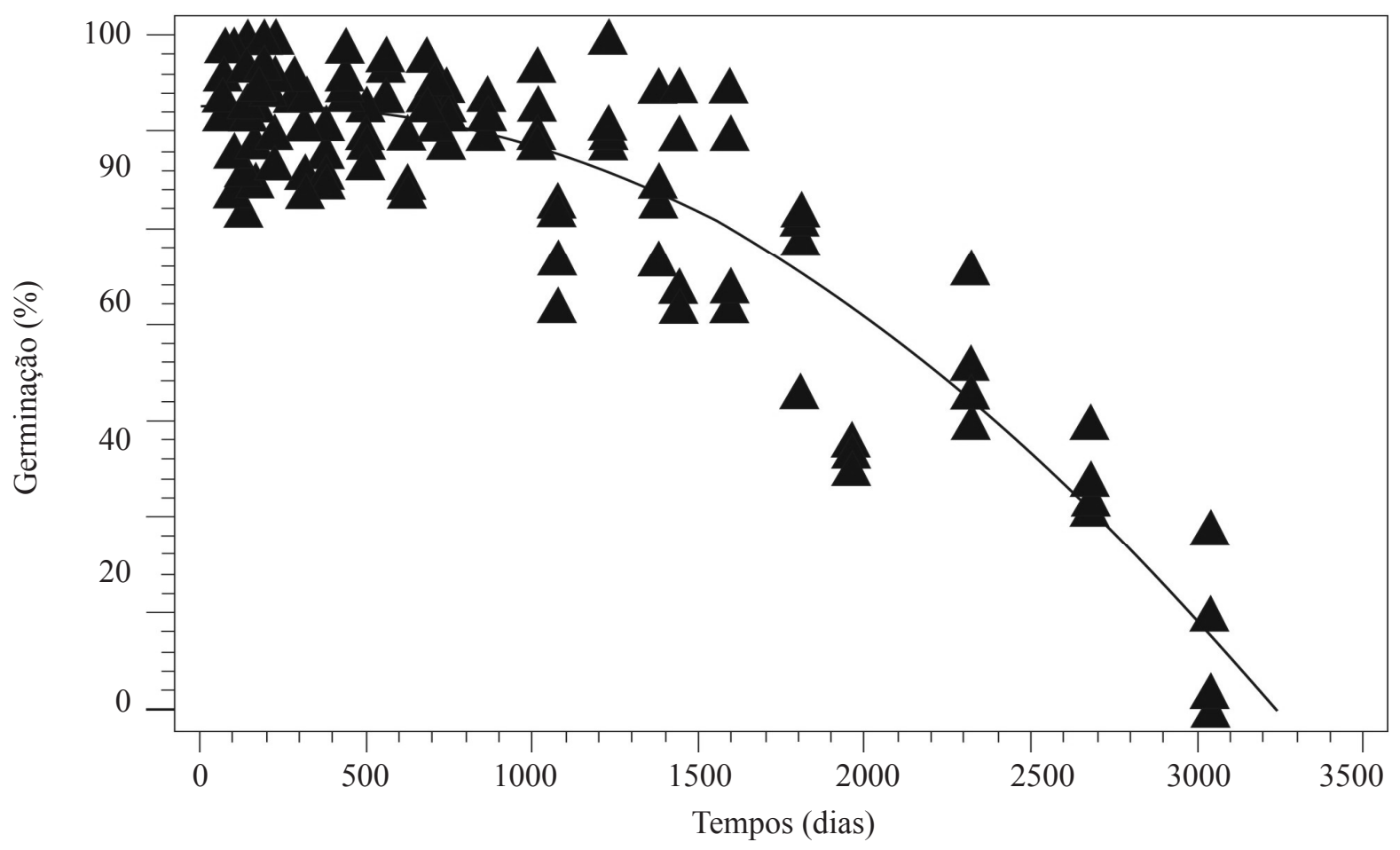

FIGURA 2. Germinação de sementes (\%) de $M$. minutiflora variedade Roxo a $20 / 30{ }^{\circ} \mathrm{C}$, em presença de luz e nitrato de potássio ao longo do tempo de armazenamento em condições ambientais, em Brasília-DF. (germinação $=92.63718+0.003006 *$ Dias $\left.-6.9 \mathrm{E}-6 * \operatorname{Dias}^{2}, \mathrm{r}^{2}=0,80\right)$.

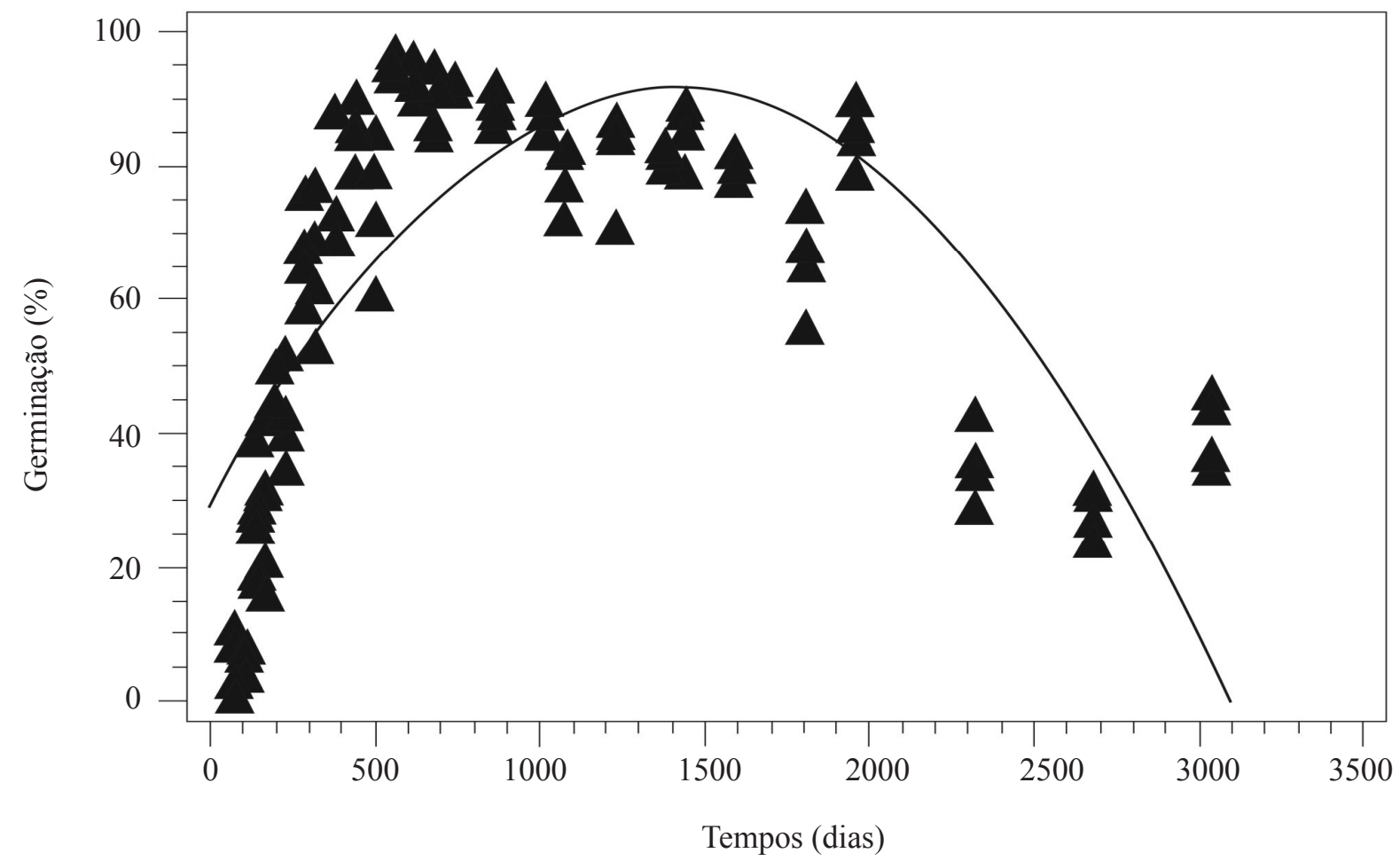

FIGURA 3. Germinação de sementes (\%) de M. minutiflora variedade Cabelo-de-Negro a $25{ }^{\circ} \mathrm{C}$, no escuro e em água ao longo do tempo de armazenamento em condições ambientais, em Brasília-DF. (germinação = $29.05031+0.089002 *$ Dias $\left.-0.000032 * \operatorname{Dias}^{2}, r^{2}=0,59\right)$. 


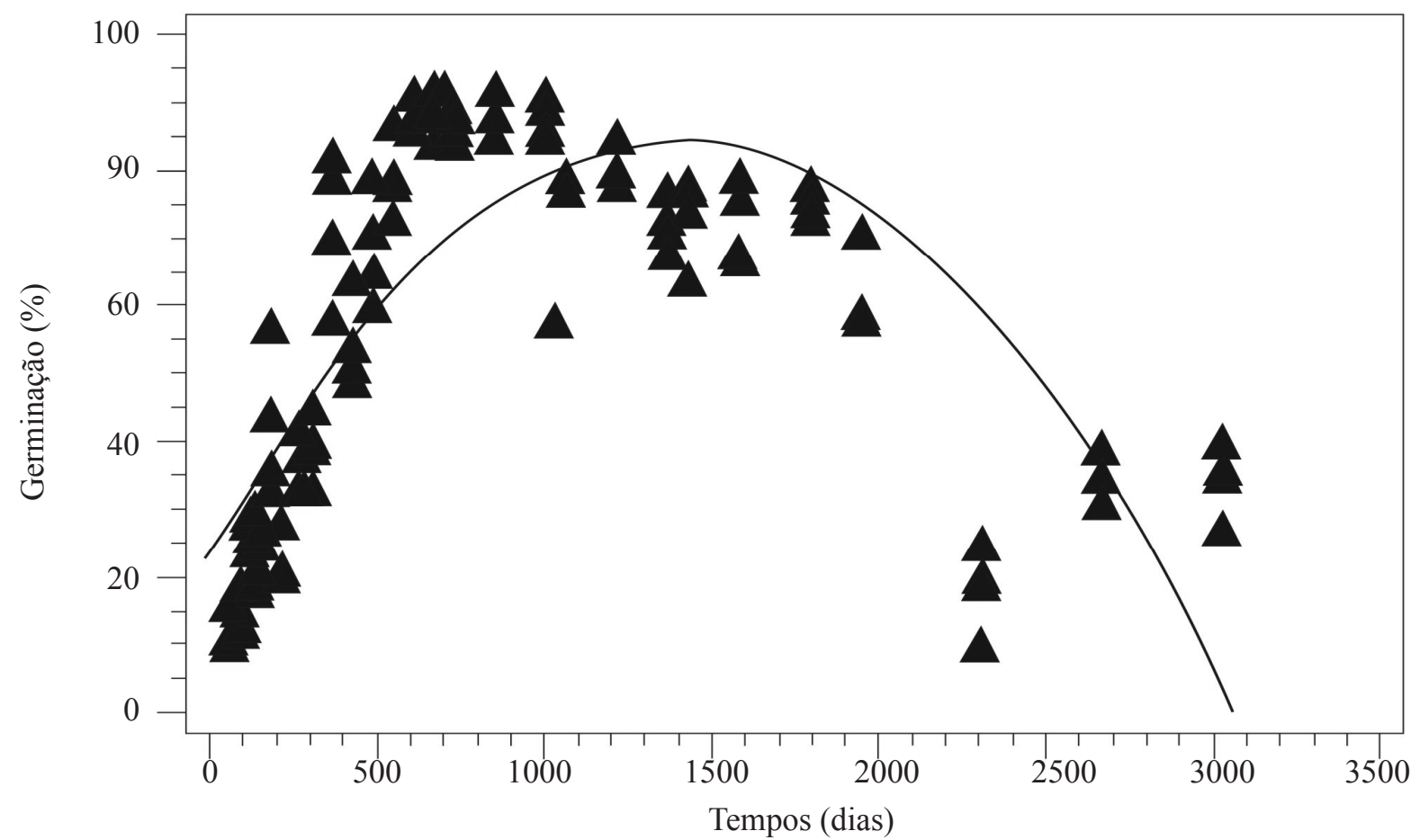

FIGURA 4. Germinação de sementes (\%) de $M$. minutiflora variedade Roxo a $25^{\circ} \mathrm{C}$, no escuro ao longo do tempo de armazenamento em condições ambientais em Brasília-DF. (germinação $=22.56982+0.086696 *$ Dias $\left.-0.000031 * \operatorname{Dias}^{2}, r^{2}=0,61\right)$.

As condições de temperaturas alternadas com luz e nitrato de potássio foram eficientes na estimativa da viabilidade das sementes de capim-gordura ao longo do período estudado (Figuras 1 e 2). Martins et al. (2004) também observaram germinação superior a $90 \%$ em sementes das cultivares Roxo e Cabelo-de-Negro de M. minutiflora nessas mesmas condições, aos quatro meses após colheita. No regime de alternância de temperaturas de $15^{\circ}-35^{\circ} \mathrm{C}$ (8/16 horas), em água, com luz, tanto as sementes recém-colhidas de $M$. minutiflora como as armazenadas por seis meses germinaram acima de $80 \%$, o que mostra que essas condições também são favoráveis a germinação das sementes dessa espécie (Freitas \& Pivello, 2005).

O processo germinativo das sementes de capim-gordura é bastante sincronizado e rápido, iniciando aos três dias após a montagem do teste e se estendendo durante 8 dias. O tempo médio de germinação das sementes foi de 4,3 e de 4,4 dias para as cultivares Roxo e Cabelo-de-Negro, respectivamente (Tabela 2). Esse comportamento é típico de espécies definidas como invasoras (Maillet \& López-Garcia, 2000).

TABELA 2. Tempo necessário para a germinação de sementes de Melinis minutiflora (capim-gordura), cultivares Roxo e Cabelo-de-Negro, sob temperaturas alternadas $\left(20^{\circ}-30^{\circ} \mathrm{C}\right)$, luz e nitrato de potássio. Sementes coletadas no ano de 1999 no Parque Nacional de Brasília, DF.

\begin{tabular}{cccc}
\hline Cultivares & $\begin{array}{c}\text { Dias necessários para início da } \\
\text { germinação }\end{array}$ & $\begin{array}{c}\text { Duração do processo } \\
\text { germinativo (dias) }\end{array}$ & TMG* $^{*}$ \\
\hline $\begin{array}{c}\text { Melinis minutiflora } \\
\text { cv. Roxo }\end{array}$ & 3 & $7,8( \pm 4,3)$ & $4,3( \pm 1,3)$ \\
$\begin{array}{c}\text { Melinis minutiflora } \\
\text { cv. Cabelo-de-Negro }\end{array}$ & 3 & $8,3( \pm 4,9)$ & $4,4( \pm 1,5)$ \\
\hline
\end{tabular}

(*) TMG = tempo médio de germinação, expresso em dias. 
Por outro lado, a germinação de sementes recémcolhidas das duas cultivares foi baixa em temperatura constante $\left(25^{\circ} \mathrm{C}\right)$, ausência de luz e em água (Figuras 3 e 4 ). Na temperatura de $20^{\circ} \mathrm{C}$, Martins et al. (2004) observaram germinação ao redor de $30 \%$ para essas duas variedades. Com o passar do tempo em armazenamento, a germinação das sementes de ambas cultivares foi aumentando até atingir um máximo, a partir do qual começou a decair até níveis bastante baixos (Figuras 3 e 4). Aparentemente, essas condições foram adequadas para avaliar a dormência das sementes. Sementes recém-colhidas apresentaram níveis acentuados de dormência primária (ou inata) quando avaliadas nessas condições. Com o passar do tempo em armazenamento, o nível de dormência das sementes foi declinando, o que pode ser confirmado com o aumento da germinação nas condições de temperatura constante. A germinação máxima nessas condições ocorreu aos 3,8 anos após colheita para as duas cultivares (ponto em que a derivada da equação da germinação em temperatura constante ao longo do tempo igualou-se a zero). A partir desse ponto, a germinação nessas condições declinou de forma semelhante ao ocorrido nas condições de temperaturas alternadas. Dessa forma, conclui-se que, na ausência de dormência, as sementes de $M$. minutiflora germinam bem tanto nas condições de temperaturas alternadas como nas de temperatura constante testadas.

A dormência das sementes é documentada para um grande número de espécies tropicais (Dias, 2005; Ikeda et al., 2008a; Ikeda et al., 2008b), e o mecanismo de inibição da germinação parece ser uma importante estratégia de sobrevivência, que favorece a persistência do banco de sementes (Benvenutti, et al., 2001; Williams et al., 2003). O período de duração da dormência primária é bastante variável entre as espécies. De acordo com Dias (2005), sementes de gramíneas forrageiras, normalmente, têm um período curto de dormência (geralmente, cerca de três a seis meses), de modo que o intervalo de tempo compreendido entre a colheita e o uso das sementes é suficiente para que, por ocasião da semeadura, estas não tenham mais dormência. Nesse caso, o agricultor não precisa utilizar tratamentos para a superação da dormência antes da semeadura. No entanto, para algumas gramíneas forrageiras tropicais, o estabelecimento de pastagens é dificultado pela dormência acentuada das sementes. Esse é o caso da Brachiaria dyctioneura, cv. Llanero, cujas sementes podem apresentar dormência até um ano depois de colhidas, acarretando problemas durante o estabelecimento da pastagem. Em $M$. minutiflora esse tempo é ainda maior ( 3,8 anos), o que pode explicar, em parte, o sucesso dessa espécie em colonizar áreas de conservação da natureza, garantindo o potencial regenerador do banco de sementes durante um período prolongado.

\section{CONCLUSÕES}

Sementes recém-colhidas de capim-gordura, cultivares Roxo e Cabelo-de-Negro, apresentam viabilidade próxima a $100 \%$ e elevado índice de dormência primária.

Nas condições ambientais predominantes em BrasíliaDF, a viabilidade das sementes dessas cultivares de capim-gordura permanece elevada (igual ou superior a 90\%) pelo período de pelo menos três anos após colheita, mantendo capacidade germinativa de cerca de $40 \%$ das sementes mesmo após oito anos de armazenamento nessas condições.

Sob alternância de temperaturas $\left(20-30{ }^{\circ} \mathrm{C}\right)$ com luz e em presença de nitrato de potássio, sementes de M. minutiflora germinam rapidamente (tempo médio de germinação de 4,3 dias para a cultivar Roxo e de 4,4 dias para a cultivar Cabelo-de-Negro).

É necessário o período de 3,8 anos em armazenamento para a superação total da dormência das sementes de capimgordura quando a dormência é testada a $25^{\circ} \mathrm{C}$, em água e no escuro.

\section{AGRADECIMENTOS}

Ao ICMBio - Instituto Chico Mendes de Conservação da Biodiversidade / Parque Nacional de Brasília, pela autorização para realizar da pesquisa nessa unidade de conservação. À professora Concepta Macmanus Pimentel, pelo auxílio nas análises estatísticas.

\section{REFERÊNCIAS}

ANDRADE, R.V.Épocas de colheita, produção e qualidades de sementes de capim-gordura. Revista Brasileira de Sementes, v.5, p.9-22, 1983.

BENVENUTTI, S.; MACCHIA, M.; MIELE, S. Quantitative analysis of emergence of seedlings from buried weed seeds with increasing soil depth. Weed Science, v.49, p.528-535, 2001.

BRASIL. Ministério da Agricultura, Pecuária e Abastecimento. Regras para análise de sementes. Ministério da Agricultura, Pecuária e Abastecimento. 
Secretaria de Defesa Agropecuária. Brasília, DF: Mapa/ ACS, 2009. 395p.

CARVALHO, M.M.; BOTREL, M.A.; MARTINS, C.E. Recuperando pastagens em áreas de morro e em solos ácidos. Balde Branco, p.22-24, 1988.

CARMONA, R.; MARTINS, C.R. Efeito do local de coleta nas características de sementes de capim-gordura (Melinis minutiflora P. Beauv.) no Distrito Federal, Brasil. Revista Brasileira de Sementes, v.31, n.3, p.167-172, 2009.

CARMONA, R.; MARTINS, C.R.; FÁVERO, A.P. Fatores que afetam a germinação de sementes de gramíneas nativas do cerrado. Revista Brasileira de Sementes, v.20, n.1, p.16-22, 1998.

CARMONA, R.; MARTINS, C.R.; FÁVERO, A.P. Características de sementes de gramíneas nativas do cerrado. Pesquisa Agropecuária Brasileira, v.34, p.10671074, 1999.

CARMONA, R.; MURDOCH, A.J. Interactions of temperature and dormancy-relieving compounds on the germination of weed seeds. Seed Science Research, v.5, p.227-236, 1995.

CONDÉ, A. DOS R.; GARCIA, J. Efeito da época de colheita sobre o potencial de armazenamento das sementes do capim-braquiária, em condições ambientais. Revista Brasileira de Sementes, v.7, p.85-92, 1985.

DIAS, D.C.F.S. Dormência em sementes: mecanismos de sobrevivência das espécies. Seed News, v.4, p.1-4, 2005.

EIRA, M.T.S. Comparação de métodos de quebra de dormência em sementes de capim Andropogon. Revista Brasileira de Sementes, v.5, p.37-49, 1983.

FILGUEIRAS, T.S. Africanas no Brasil. Gramíneas introduzidas da África. Cadernos de Geociências, v.5, p.57-63, 1990.

FILGUEIRAS, T.S. Asiáticas no Brasil: gramíneas (Poaceae) introduzidas da Ásia. EUGENIANA, v28, p.318, 2005.

FREITAS, G.K.; PIVELLO, V.R. A ameaça das gramíneas exóticas à biodiversidade. In: PIVELLO, V.R.; VARANDA, E. M. (Ed.). O cerrado Pé-de-Gigante: ecologia e conservação - Parque Estadual de Vassununga. São Paulo: SMA, 2005. p.240-270.

IKEDA, F.S.; CARMONA, R.; MITJA, D.; GUIMARÃES, R.M. Luz e KNO3 na germinação de sementes de Ageratum conyzoides L. sob temperaturas constantes e alternadas. Revista Brasileira de Sementes, v.30, p.193-199, 2008a.
IKEDA, F.S.; CARMONA, R.; MITJA, D.; GUIMARÃES, R.M. Luz e KNO3 na germinação de sementes de Tridax procumbens sob temperatura constante e alternada. Planta Daninha, v.26, p.751-756, 2008b.

INSTITUTO NACIONAL DE METEREOLOGIA INMET. Disponível em: <http://www.inmet.gov.br/html/ clima>. Acesso em: 29 Julho 2010.

KLINK, C.A. Germination and seedling establishment of two native and one invading African grass species in the Brazilian cerrado. Journal of Tropical Ecology, v.21, p.139-147, 1996.

MACEDO, M.C. Sistemas de produção em pasto nas savanas da América Tropical: limitações a sustentabilidade. In: Reunião Latinoamericana de Produccion Animal, 16; Congreso Uruguayo de produccion Animal, 3, 2000, Montevideo. Anales... Argentina: Alpa. Delmercosur.com, 2000. CD-ROM. Conferencias.

MACEDO, M.C. Pastagens no ecossistema Cerrados: evolução das pesquisas para o desenvolvimento sustentável. In: A produção animal e o foco no agronegócio. Anais... Goiânia. 42a Reunião Anual da SBZ, 2005. p.56-84.

MAILLET, J.; LÓPEZ-GARCIA, C. What criteria are relevant for predicting the invasive capacity of a new agricultural weed ? The case of invasive American species in France. Weed Research, v.40, p.11-29, 2000.

MARTINS, C.R.; HAY, J.D.V.; CARMONA, R.; LEITE, R.R.; SCALÉA, M.; VIVALDI, L.J.; PROENÇA, C.E.B. Monitoramento e controle da gramínea invasora Melinis minutiflora (capim-gordura) no Parque Nacional de Brasília, Distrito Federal. In: IV CONGRESSO BRASILEIRO DE UNIDADES DE CONSERVAÇÃO, 2004, Curitiba. Seminário 2. Anais... Fundação O Boticário de Proteção à Natureza: Rede Nacional Pró Unidade de Conservação, 2004, p.85-96.

MARTINS, C.R.; HAY, J.V.; CARMONA, R. Potencial invasor de duas cultivares de Melinis minutiflora no cerrado brasileiro - características de sementes e estabelecimento de plântulas. Revista Árvore, v.33, p.713-722, 2009.

ROCHA, G.L.; CINTRA, B.; FREIRE, A.; MONTANGUININI, M.F. Estudo da variação do teor germinativo de sementes de capim-gordura (Melinis minutiflora) armazenadas a baixas temperaturas e em ambiente normal. In: CONGRESSO INTERNACIONAL DE PASTAGENS, 9,. 1996, São Paulo1996 São Paulo: Anais... Secretaria da Agricultura, 1996. p.531-534.

SADER, R.G.E.A.; MATTOS, JR. D.; PEREIRA, C.P.; MELLO, F.A.A. Efeito da mistura de fertilizantes fosfatados 
na germinação de sementes de Brachiaria brizantha (Hochst ex. A. Rich) Staf e de Brachiaria decumbens Staf. Revista Brasileira de Zootecnia, v.13, p.37-43, 1991.

SKERMAN, P.J.; RIVERS, F.R. Gramineas Tropicales. Colección FAO: Producción y protección vegetal. n.23, 1992, Roma. 849p.
TEIXEIRA, M.R.O. Avaliação da variabilidade genética de coletas de capim-gordura (Melinis minutiflora Beauv.) em solo submetido a diferentes graus de compactação. 1984. 62f. Dissertação de Mestrado. Universidade Federal de Viçosa, Viçosa, 1984.

WILLIAMS, P.R.; CONGDON, R.R.; GRICE，A.C.; CLARKE, P.J. Fire-related cues break seed dormancy of six legumes of tropical eucalypt savannas in North-eastern Australia. Austral Ecology, v.28, p.507-514, 2003. 